\title{
Elevated levels of mRNAs encoding dihydropyrimidine dehydrogenase and thymidylate synthase are associated with improved survival of patients with hepatocellular carcinoma treated with S-1
}

\author{
YUSUKE OKANO $^{1}$, HIDEKAZU KURAMOCHI ${ }^{2,3}$, GO NAKAJIMA ${ }^{2}$, \\ SATOSHI KATAGIRI $^{1,3}$ and MASAKAZU YAMAMOTO ${ }^{1}$ \\ ${ }^{1}$ Department of Surgery, Institute of Gastroenterology; ${ }^{2}$ Department of Chemotherapy and Palliative \\ Care, Tokyo Women's Medical University, Shinjuku-ku, Tokyo 162-8666; ${ }^{3}$ Department of Surgery, \\ Tokyo Women's Medical University, Yachiyo Medical Center, Yachiyo, Chiba 276-8524, Japan
}

Received September 12, 2015; Accepted March 9, 2017

DOI: $10.3892 / \mathrm{ol} .2017 .6241$

\begin{abstract}
Thymidylate synthase (TYMS) and dihydropyrimidine dehydrogenase (DPYD) are associated with the response of tumors to fluoropyrimidines. The aim of the present study was to investigate the association between the levels of TYMS and DPYD mRNAs and the efficacy of S-1 for treating patients with HCC. A total of 35 patients with HCC who received S-1 upon recurrence (S-1 group) and 20 patients who never received a fluoropyrimidine (control group) were studied. The levels of TYMS and DPYD mRNA in surgically resected specimens were determined using reverse transcription-polymerase chain reaction assays. Overall survival (OS) time of S-1 group patients with high levels of $D P Y D$ mRNA was significantly longer compared with that of patients with low levels (median 501 days vs. 225 days; $P=0.016$ ). Similarly, the OS time of those patients with high levels of TYMS mRNA was significantly longer compared with those with low levels (median 503 days vs. 239 days; $\mathrm{P}=0.0076$ ). By contrast, there was no difference in OS time of the control group between patients with high and low levels of DPYD and TYMS mRNAs. The levels of TYMS and DPYD mRNAs may serve as predictive markers for patients with $\mathrm{HCC}$ who receive S-1 chemotherapy.
\end{abstract}

\section{Introduction}

Hepatocellular carcinoma (HCC) is the third most lethal cancer worldwide, with the highest incidence in East Asia (1).

Correspondence to: Dr Hidekazu Kuramochi, Department of Surgery, Tokyo Women's Medical University, Yachiyo Medical Center, 477-96 Owadashinden, Yachiyo, Chiba 276-8524, Japan E-mail: kuramochi.hidekazu@twmu.ac.jp

Key words: hepatocellular carcinoma, thymidylate synthase, dihydropyrimidine dehydrogenase, S-1
Radical resection is the principal treatment for HCC, but the recurrence rate is very high (2). Radiofrequency ablation (RFA) and transcatheter arterial chemoembolization (TACE) may be performed to treat intrahepatic recurrence, but only systemic chemotherapy can be employed for extrahepatic recurrence (3). In a phase III trial, sorafenib was the only drug that prolonged the overall survival (OS) time of patients with HCC (4,5). However, the difference in median OS time between the patients treated with sorafenib, which is very expensive, and best supportive care was only 2 months.

$\mathrm{S}-1$ is a novel, orally administered drug that combines the components (in a molar concentration ratio of 1:0.4:1) as follows: Tegafur, a metabolically activated prodrug of 5-fluorouracil (5-FU); 5-chloro-2,4-dihydropyridine, a reversible dihydropyrimidine dehydrogenase (DPYD) inhibitor; and oteracil potassium (6). Several case studies show a marked response of patients with HCC to S-1 (7-9). Although a phase I/II study of S-1 in patients with advanced HCC showed promising antitumor activity with acceptable toxicities (10), a phase III randomized study of S-1 in patients with sorafenib refractory advanced HCC failed to show clinical advantage (11). Thus, selection of the patients with HCC who will gain clinical benefit from S-1 treatment is required.

Thymidylate synthase (TYMS) is the rate-limiting enzyme in the synthesis of thymine nucleotides (12). TYMS expression levels are associated with response of patients to 5-FU therapy and their prognosis, and high levels of TYMS expression in most cases are associated with worse responses and shorter survival times (12-14). DPYD, which degrades pyrimidines, uracil and thymine and inactivates $5-\mathrm{FU}$, is associated with the response to 5-FU-based therapies $(15,16)$.

Therefore, it was hypothesized that TYMS and DPYD are potential biomarkers for predicting the efficacy of S-1 for treating patients with HCC. In the present study, 30 patients with $\mathrm{HCC}$ who were treated with $\mathrm{S}-1$ subsequent to having relapsed following surgical resection were assessed. The levels of TYMS and DPYD mRNAs in surgically resected specimens were measured using reverse transcription-quantitative 
polymerase chain reaction assays (RT-qPCR) to investigate the association of TYMS and DPYD expression with the efficacy of S-1 treatment and OS time.

\section{Materials and methods}

Characteristics of patients. A total of 55 patients with relapsed HCC were studied. All patients underwent curative liver resection at the Institute of Gastroenterology, Tokyo Women's Medical University Hospital (Tokyo, Japan) between September 1997 and January 2007. All patients subsequently relapsed following surgery. In total, 14 of these patients had hepatitis B virus, 24 had hepatitis $\mathrm{C}$ and 11 had alcoholic liver cirrhosis. A total of 35 patients received S-1 upon recurrence (S-1 group), and 20 patients never received S-1 or any fluoropyrimidine derivative (control group). S-1 was generally administrated at $80 \mathrm{mg} / \mathrm{m}^{2}$ of body surface area per day for 4 weeks followed by 2 weeks of rest, and this 6 -week cycle was repeated until the disease progressed. The dose and schedule of S-1 administration was modified based on liver function and the general condition of each patient. The patients with control group had never received systemic chemotherapy. S-1 was used following failure of local control therapy, including TACE and/or RFA. In the S-1 group, patients experienced relapses as follows: Liver, 30 (85.7\%); lung, 18 (51.4\%); lymph node, 5 (14.2\%); brain, 6 (17.1\%); bone, 8 (22.9\%); and adrenal gland, $2(5.7 \%)$. The characteristics of patients in the S-1 and control groups are shown in Table I. Clinicopathological characteristics of the S-1 group according to TYMS and DPYD mRNA levels are shown in Table II, and those of the control group are shown in Table III. Biochemical data such as serum albumin, indocyanine green retention test (ICG R15), prothrombin time, total bilirubin and cholinesterase were collected from each patient to compare the liver function between TYMS high and low expression patients, as well as dihydropyrimidine dehydrogenase (DYPD). Clinicopathological data including tumor differentiation, number of tumors, portal vein invasion, hepatic vein invasion and intrahepatic metastasis were also assessed from each patient to compare the background between TYMS high and low expression patients, as well as DYPD. Child-Pugh score was used to assess the liver function (17).

The Ethics Committee of the Tokyo Women's Medical University (Tokyo, Japan) approved the present study, which was performed in accordance with the Declaration of Helsinki. Patients granted their informed consent to be involved in the present study.

Microdissection. Formalin-fixed paraffin-embedded (FFPE) tumor specimens were cut into $10 \mu \mathrm{m}$ thick serial sections Manual microdissection was performed using a scalpel if the histology was homogeneous and the tissue contained $>90 \%$ cancer cells. For all other samples, laser-capture microdissection (P.A.L.M. Microlaser Technologies AG, Munich, Germany) was performed to ensure that only tumor cells were acquired.

RNA isolation and cDNA synthesis. RNA isolation from FFPE specimens was performed using an RNeasy FFPE kit (Qiagen, Inc., Valencia, CA, USA) according to the manufacturer's protocol. The cDNAs were synthesized using a High Capacity
cDNA Reverse Transcription kit (Applied Biosystems; Thermo Fisher Scientific, Inc., Waltham, MA, USA).

$R T$-qPCR. The cDNAs were amplified using a TaqMan PreAmp Master Mix kit (Applied Biosystems; Thermo Fisher Scientific, Inc.) according to the manufacturer's protocol. Quantification of target genes TYMS and DPYD and the internal reference gene ( $\beta$-actin, $A C T B$ ) was performed using a fluorescence-based real-time detection method (StepOne Real-time Polymerase Chain Reaction System; Applied Biosystems; Thermo Fisher Scientific, Inc.). The primers and probes used were from TaqMan Gene Expression Assays (Applied Biosystems; Thermo Fisher Scientific, Inc.) with assay IDs: Hs00426591_m1 for TYMS; Hs00559278_m1 for $D P Y D$; and Hs01060665_g1 for ACTB.

The PCR reaction mixture consisted of $10 \mu \mathrm{l}$ of TaqMan Fast Universal PCR Master Mix without uracil-N-glycosylase (Applied Biosystems; Thermo Fisher Scientific, Inc.), $5 \mu \mathrm{l}$ of amplified cDNA, $1 \mu \mathrm{l}$ of each of the TaqMan Gene Expression Assay primers and probe (20X) and $3 \mu \mathrm{l}$ of nuclease-free water. Cycling conditions were $95^{\circ} \mathrm{C}$ for $20 \mathrm{sec}$, followed by 40 cycles at $95^{\circ} \mathrm{C}$ for $1 \mathrm{sec}$ and $60^{\circ} \mathrm{C}$ for $20 \mathrm{sec}$. The threshold cycle $(\mathrm{Cq})$ value for each gene was determined using SDS software v1.2 (Applied Biosystems; Thermo Fisher Scientific, Inc.). The $\Delta-\mathrm{Cq}(\Delta \mathrm{Cq})$ value, which is the difference between the $\mathrm{Cq}$ value of the target gene and that of the endogenous reference gene, was also calculated using the same software. $\Delta-\Delta \mathrm{Cq}(\Delta \Delta \mathrm{Cq})$, which is the difference between the DCq value for each sample and the highest $\Delta \mathrm{Cq}$ value as a calibrator, was also calculated. The value of $2^{-\Delta \Delta \mathrm{Cq}}$ was used for quantitation of relative mRNA levels (18).

Statistical analysis. Comparisons of clinicopathological backgrounds were assessed using the $\chi^{2}$ test. The Kaplan-Meier method was used to generate survival curves, and the log-rank test was used to compare survival between groups. The Cox proportional hazard regression model was used in multivariate analysis. In the S-1 group, OS was defined as the time from the first day of S-1 administration to mortality from any cause. In the control group, OS was defined as the time from the day of operation to mortality from any cause. Median values were used as the cutoff values to divide high and low expression levels. $\mathrm{P}<0.05$ was considered to indicate a statistically significant difference. All values were two-sided. Statistical analyses were performed using JMP 10 (SAS Institute Inc., Cary, NC, USA).

\section{Results}

Treatment of the S-1 group. A total of 35 patients with HCC in the $\mathrm{S}-1$ group received S-1 upon recurrence of disease. Median treatment time was 12 weeks, and the mean dose administered was $89.6 \mathrm{mg} /$ day. Grade 1 or 2 gastrointestinal adverse events were most common, but grade 3 or 4 never occurred. A total of 3 patients stopped receiving S-1 due to fatigue, appetite loss or diarrhea.

Gene expression and survival time of the $S-1$ group. The median level of DPYD mRNA was 11.31 (range, 2.36-23.92), and the median level of TYMS mRNA was 5.46 
Table I. Characteristics of patients.

\begin{tabular}{lcc}
\hline Characteristic & S-1 group & Control group \\
\hline Total number of patients & 35 & 20 \\
Host factors & & 59.6 \\
Age, years (median) & $29 / 6$ & $16 / 4$ \\
Sex (M/F) & 5.4 & 5.6 \\
Child Pugh Score & $12 / 14$ & $2 / 14$ \\
Viral hepatitis (B/C) & 5 & 6 \\
Alcoholic hepatitis & $23 / 4$ & $13 / 7$ \\
Liver status (Chronic hepatits/liver cirrhosis) & & \\
Recurrent site & $30(85.7 \%)$ & $18(90 \%)$ \\
Liver & $18(51.4 \%)$ & $8(40 \%)$ \\
Lung & $8(22.9 \%)$ & $6(30 \%)$ \\
Bone & $6(17.1 \%)$ & $2(10 \%)$ \\
Brain & $5(14.2 \%)$ & $3(15 \%)$ \\
Lymph node & $1(5.7 \%)$ & $0(0 \%)$ \\
Adrenal gland & & $2,117(14-18,500)$ \\
Blood serum test & $8,502(2-83,069)$ & $7,827(2-113,156)$ \\
AFP (ng/ml) & $12,345(5-277,820)$ & 2 \\
PIVKA II (U/ml) & & \\
\end{tabular}

AFP, $\alpha$-fetoprotein; PIVKA II, prothrombin induced by vitamin K absence-II; M, male; F, female.

TYMS

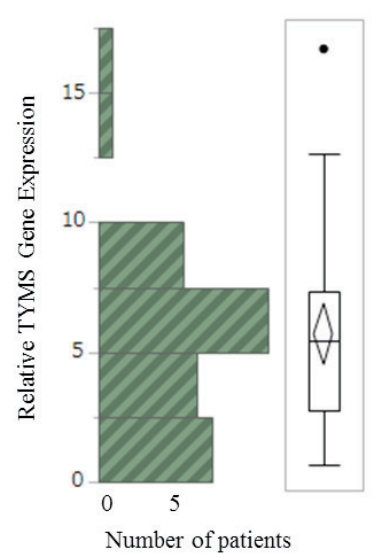

DPYD

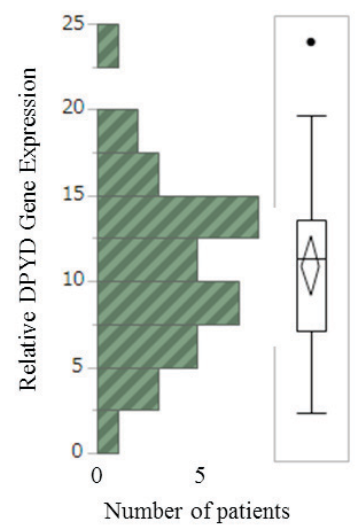

Figure 1. Bar chart and box-and-whisker plots of relative TYMS and $D P Y D$ mRNA expression levels in the S-1 group, as determined by reverse transcription-quantitative polymerase chain reaction. TYMS, thymidylate synthase; DPYD, dihydropyrimidine dehydrogenase.

(range, 0.67-16.68; Fig. 1), relative to $A C T B$. Using the median value as a cutoff, $\mathrm{S}-1$ group patients with high levels of DPYD mRNA were associated with longer overall survival time in contrast to those with low levels of DPYD mRNA [median 501 days vs. 225 days; hazard ratio (HR), 0.35 (95\% confidence interval [CI]: 0.14-0.85); $\mathrm{P}=0.016$; Fig. 2]. Similarly, the OS time of patients with high levels of TYMS mRNA was significantly longer compared with those with low levels of TYMS mRNA (median 503 days vs. 239 days; HR 0.29 [95\% CI, 0.100-0.726) $\mathrm{P}=0.0076$; Fig. 3]. The results of multivariate analysis indicated that the levels of TYMS and DPYD mRNA were significant independent prognostic variables (TSYD, $\mathrm{P}=0.013 ; D P Y D, \mathrm{P}=0.0171)$ in contrast to age, number of tumors and Child-Pugh score (17).

Gene expression and survival time of the control group. The gene expression data raised the question of whether the levels of TYMS and DPYD mRNA are predictive markers for the efficacy of S-1 therapy or prognostic markers regardless of administration of S-1. To answer this question, the levels of TYMS and DPYD mRNAs were determined in 20 patients with relapsed $\mathrm{HCC}$ who never received $\mathrm{S}-1$ or any fluoropyrimidine as a control group. Overall survival time of this group was calculated from the day of curative surgery to mortality. There was no significant difference in OS time between patients in the control group with high or low levels of DPYD mRNA [median, 1,466 vs. 1,391 days; HR 1.69 (95\% CI: 0.60-5.11); $\mathrm{P}=0.32$; Fig. 4], indicating that the levels of $D P Y D$ mRNA are a predictive marker of $\mathrm{S}-1$ efficacy and not a prognostic marker of HCC. There was a tendency for longer survival time in the high group compared with the low group that was not statistically significant [median 1,729 vs. 1,094 days; HR $0.48(95 \%$ CI: 0.14-1.44), $\mathrm{P}=0.19$; Fig. 5].

Analysis of clinicopathological parameters according to TYMS and DPYD mRNA expression in each group. The survival time of the patients with HCC depends not only on cancer progression but also on liver dysfunction, since the majority of patients with HCC have liver cirrhosis (17). To determine whether the levels of TYMS and DPYD mRNA were associated with liver function, patients' values of 
Table II. Clinicopathological characteristics of the S-1 group.

\begin{tabular}{|c|c|c|c|c|c|c|}
\hline Characteristic & TYMS high & TYMS low & P-value & DPYD high & DPYD low & P-value \\
\hline Age, years ${ }^{\mathrm{a}}$ & $65(42-76)$ & $60(31-72)$ & 0.57 & $65(42-76)$ & $59(31-72)$ & 0.24 \\
\hline \multicolumn{7}{|c|}{ Liver function parameters } \\
\hline \multicolumn{7}{|l|}{ Child Pugh score } \\
\hline A & 13 & 13 & 0.77 & 15 & 15 & 0.68 \\
\hline B & 4 & 5 & & 3 & 2 & \\
\hline Albumin, $\mathrm{g} / \mathrm{dl} \mathrm{l}^{\mathrm{a}}$ & $4.0(3.3-4.5)$ & $3.8(2.8-4.8)$ & 0.28 & $3.95(2.8-4.5)$ & $3.8(2.8-4.8)$ & 0.64 \\
\hline Cholinesterase, IU/1 & $221(116-321)$ & $226(65-316)$ & 0.77 & $225(102-321)$ & $226(65-316)$ & 0.85 \\
\hline ICG R15, \% ${ }^{\mathrm{a}}$ & $13(4-28)$ & $8.5(3-32)$ & 0.08 & $14(4-28)$ & $9(3-32)$ & 0.10 \\
\hline Prothrombin time, $\%^{a}$ & $88.3(40.6-100)$ & $87.7(59.4-100)$ & 0.89 & $84.4(40.6-100)$ & $91.1(71.1-100)$ & 0.36 \\
\hline \multicolumn{7}{|l|}{ Tumor pathology } \\
\hline \multicolumn{7}{|l|}{ Differentiation } \\
\hline Well & 0 & 2 & 0.41 & 0 & 2 & 0.32 \\
\hline Moderate & 13 & 14 & & 15 & 12 & \\
\hline Poor & 3 & 3 & & 3 & 3 & \\
\hline \multicolumn{7}{|l|}{ Number of tumors } \\
\hline Solitary & 11 & 12 & 0.73 & 13 & 11 & 0.33 \\
\hline Multiple & 5 & 7 & & 4 & 7 & \\
\hline \multicolumn{7}{|l|}{ Portal vein invasion } \\
\hline Yes & 4 & 7 & 0.38 & 5 & 6 & 0.71 \\
\hline No & 11 & 10 & & 11 & 10 & \\
\hline \multicolumn{7}{|l|}{ Hepatic vein invasion } \\
\hline Yes & 5 & 0 & 0.02 & 5 & 0 & 0.04 \\
\hline No & 10 & 17 & & 11 & 16 & \\
\hline \multicolumn{7}{|l|}{ Intrahepatic metastasis } \\
\hline Yes & 4 & 7 & 0.39 & 4 & 7 & 0.26 \\
\hline No & 11 & 10 & & 12 & 9 & \\
\hline
\end{tabular}

${ }^{a}$ Data represented as median (range). Child Pugh score (17): A, the sum of the score is 5-6 points; B, the sum of the scores is 7-9 points. N.S., no significance; ICG R15, indocyanine green retention test; DPYD, dihydropyrimidine dehydrogenase; TYMS, thymidylate synthase.

serum albumin, indocyanine green retention test (ICG R15), prothrombin time, total bilirubin and cholinesterase were analyzed. No significant association was observed between each of these variables and levels of either of the mRNAs (Tables II and III).

Tumor differentiation, number of tumors, portal vein invasion, hepatic vein invasion and intrahepatic metastasis were assessed. A significant difference was observed in the incidence of hepatic vein invasion in the S-1 group between patients with high and low levels of TYMS mRNA $(\mathrm{P}=0.015)$ and high and low levels of DPYD mRNA ( $\mathrm{P}=0.043)$ (Table II), although the difference was increased in the TYMS high and DPYD high patients, which showed favorable outcomes. The values of all other parameters were not significantly different between the TYMS high and low or the DPYD high and low in S-1 and control groups (Tables II and III).

\section{Discussion}

In the present study, high levels of TYMS and DPYD mRNAs were associated with a significantly longer OS time in patients with HCC treated with S-1. Using qPCR, Nii et al (19) measured TYMS and DPYD mRNA levels in 74 patients with HCC and demonstrated that the OS time of patients with high levels of DPYD mRNA was significantly longer compared with patients with low levels of DPYD mRNA. These findings are in complete agreement with those of the present study. They also reported that the prognosis of patients with high levels of TYMS mRNA is more favorable compared with those with low levels, although the difference was not statistically significant. They showed that low levels of DPYD mRNA associate significantly with advanced clinical stage, undifferentiated histology, microscopic intrahepatic metastasis and a high Ki-67 labeling index, which lead to poor prognosis. The present study demonstrated that there was no significant association between the expression of each mRNA and differentiation of the tumor, vessel invasion, intrahepatic metastasis and liver cirrhosis severity (Child-Pugh score). Although, DPYD mRNA expression is lower in HCC tissues compared with that of normal liver tissue (20), there is no consensus on whether the grade of HCC is associated with DPYD mRNA expression.

To determine whether the levels of TYMS and DPYD mRNA were associated with effectiveness of S-1 chemotherapy (predictive marker) or tumor biology (prognostic 


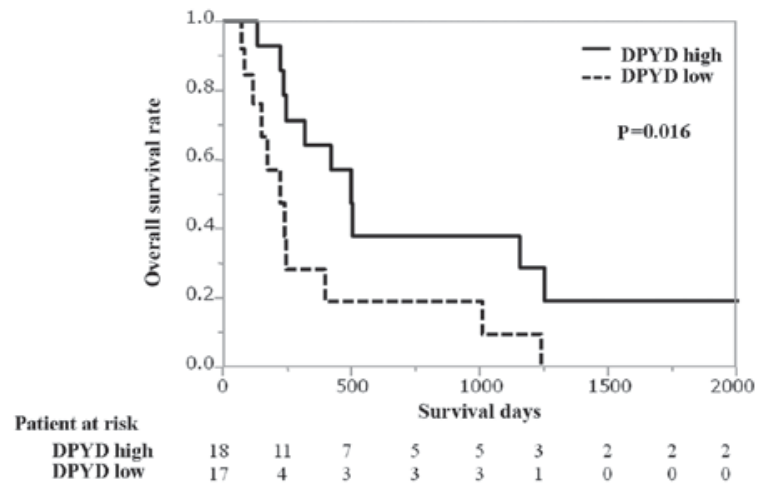

Figure 2. DPYD mRNA expression and OS rate in the S-1 group. OS rate of patients with high $D P Y D$ mRNA expression was longer compared with that of patients with low DPYD $(\mathrm{P}=0.016)$. OS, overall survival; DPYD, dihydropyrimidine dehydrogenase.

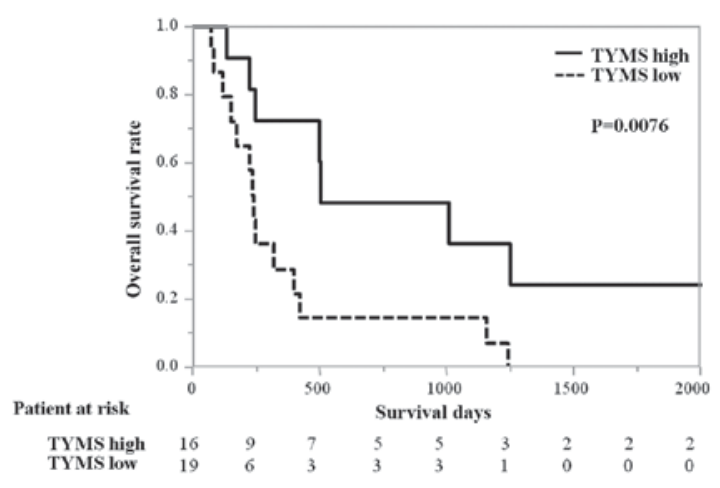

Figure 3. TYMS mRNA expression and OS rate in the S-1 group. The OS rate of the patients with high TYMS mRNA expression was longer compared with that of patients with low TYMS $(\mathrm{P}=0.0076)$. OS, overall survival; TYMS, thymidylate synthase.

marker), the levels of TYMS and DPYD were determined in patients with HCC who did not receive S-1 or therapy with any fluoropyrimidine. There was no significant association between the levels of DPYD mRNA and prognosis of the control group, indicating that DPYD mRNA levels are a predictive marker for S-1 therapy, but not as a prognostic marker. However, the present study was limited due to its small sample size.

Evidence supports the theory that high levels of TYMS expression contribute to resistance to 5-FU and that patients with low levels of TYMS mRNA respond favorably to treatment with fluoropyrimidines $(12,14,21,22)$. This is explained by the theory that the 5-FU metabolite 5-fluorodeoxyuridine monophosphate forms a ternary complex with TYMS and folic acid, which depletes TYMS, leading to the inhibition of DNA synthesis by tumor cells.

By contrast, several studies demonstrate the opposite result that high levels of TYMS expression predict a favorable outcome for patients who are treated with fluoropyrimidines $(23,24)$. TYMS expression levels predict the efficacy of fluoropyrimidine therapy and serve as a prognostic marker of various cancers in advanced stages $(24,25)$. In the present study, high levels of TYMS mRNA in the control group indicated a tendency for longer survival time, although the data were not statistically significant due to the limited number of

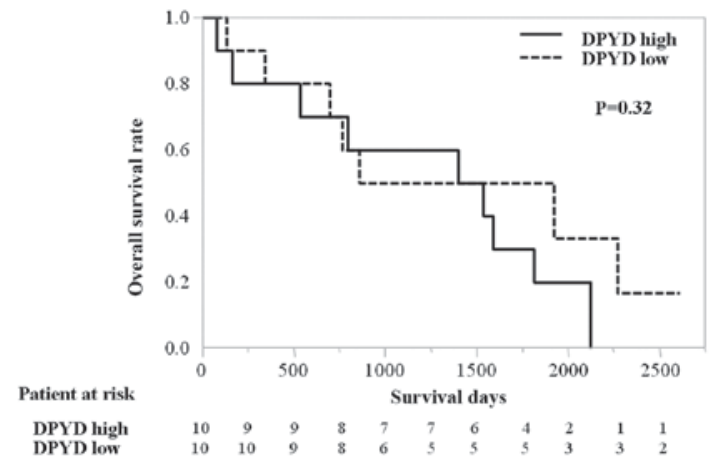

Figure 4. DPYD mRNA expression and overall survival rate in the control group. No significant difference was observed between patients with high and low DYPD mRNA expression $(\mathrm{P}=0.32)$. DPYD, dihydropyrimidine dehydrogenase.



Figure 5. TYMS mRNA expression and overall survival rate in the control group. No significant difference was observed between the patients with high and low TYMS mRNA expression $(\mathrm{P}=0.19)$. TYMS, thymidylate synthase.

samples. Thus, TYMS mRNA levels may have potential to be a prognostic marker of $\mathrm{HCC}$ independent of whether patients undergo chemotherapy. However, further larger studies were warranted.

The main cytotoxic component of S-1 is tegafur, which is a prodrug of 5-FU (6). 5-FU is mainly metabolized in the liver and may therefore be difficult to administer to patients with liver dysfunction (6). However, previous studies show promising efficacy of S-1 for treating patients with HCC (7-9). In a phase I/II study of S-1 therapy administered to patients with HCC, the response rate was $21.7 \%$, and progression-free survival and OS times were 3.7 months and 16.6 months, respectively (10). The survival data are comparable with the outcomes of sorafenib treatment of a cohort of Japanese patients with HCC (26). There is no cytotoxic drug with convincing evidence of efficacy when used systemically to treat HCC. A previous study reported that phase III randomized study of S-1 in patients with sorafenib refractory advanced HCC failed to show clinical advantage (11). Therefore, TYMS, DPD or other biomarkers are anticipated to select the patients who may obtain clinical benefit.

In conclusion, the present assessed the utility of TYMS and $D P Y D$ mRNAs as potential biomarkers for patients with HCC who were treated with S-1. These data require confirmation by conducting a large clinical trial. 
Table III. Clinicopathological characteristics of the control group $(n=20)$.

\begin{tabular}{|c|c|c|c|c|c|c|}
\hline Characteristic & TYMS high, $\mathrm{n}$ & TYMS low, n & P-value & DPYD high, $\mathrm{n}$ & DPYD low, n & P-value \\
\hline Age, years ${ }^{\mathrm{a}}$ & $66(59-81)$ & $57.5(53-78)$ & 0.05 & $64.5(53-80)$ & $63.5(53-81)$ & 0.90 \\
\hline \multicolumn{7}{|c|}{ Liver function parameters } \\
\hline \multicolumn{7}{|l|}{ Child Pugh score } \\
\hline A & 9 & 8 & 0.53 & 8 & 9 & 0.53 \\
\hline $\mathrm{B}$ & 1 & 2 & & 2 & 1 & \\
\hline Albumin, $\mathrm{g} / \mathrm{dl}^{\mathrm{a}}$ & $4(3.2-4.2)$ & $3.65(3.1-4.2)$ & 0.20 & $3.8(3.1-4.2)$ & $3.65(3.1-4.2)$ & 0.59 \\
\hline Cholinesterase, IU/1 ${ }^{\mathrm{a}}$ & $243(82-318)$ & $178(45-282)$ & 0.15 & $190.5(82-318)$ & $243(45-296)$ & 0.31 \\
\hline ICG R15, \% & $10(2.2-47)$ & $20(7-59)$ & 0.07 & $19(2.2-30)$ & $13(5-59)$ & 0.71 \\
\hline Prothrombin time, $\%^{\mathrm{a}}$ & $84.9(81.9-100)$ & $94.7(60.4-100)$ & 0.68 & $90.15(66.3-100)$ & $85(60.4-100)$ & 0.70 \\
\hline \multicolumn{7}{|l|}{ Tumor pathology } \\
\hline \multicolumn{7}{|l|}{ Differentiation } \\
\hline Well & 0 & 0 & 1.00 & 0 & 0 & 1.00 \\
\hline Moderate & 8 & 8 & & 8 & 8 & \\
\hline Poor & 2 & 2 & & 2 & 2 & \\
\hline \multicolumn{7}{|l|}{ Numbers of tumor } \\
\hline Solitary & 9 & 8 & 0.53 & 7 & 10 & 0.06 \\
\hline Multiple & 1 & 2 & & 3 & 0 & \\
\hline \multicolumn{7}{|l|}{ Portal vein invasion } \\
\hline Yes & 2 & 2 & 1.00 & 2 & 2 & 1.00 \\
\hline No & 8 & 8 & & 8 & 8 & \\
\hline \multicolumn{7}{|l|}{ Hepatic vein invasion } \\
\hline Yes & 1 & 1 & 1.00 & 0 & 2 & 0.14 \\
\hline No & 9 & 9 & & 10 & 8 & \\
\hline \multicolumn{7}{|l|}{ Intrahepatic metastasis } \\
\hline Yes & 1 & 1 & 1.00 & 0 & 2 & 0.14 \\
\hline No & 9 & 9 & & 10 & 8 & \\
\hline
\end{tabular}

${ }^{a}$ Data represented as median (range). Child Pugh score (17): A, the sum of the score is 5-6 points; B, the sum of the scores is 7-9 points. N.S., no significance; ICG R15, indocyanine green retention test; DPYD, dihydropyrimidine dehydrogenase; TYMS, thymidylate synthase.

\section{Acknowledgements}

The present study was checked by Edanz English Language Services. The authors thank Dr Shunichi Ariizumi for his careful review of the manuscript. The present study was financially supported by departmental funds from the Tokyo Women's Medical University.

\section{References}

1. Altekruse SF, McGlynn KA and Reichman ME: Hepatocellular carcinoma incidence, mortality, and survival trends in the United States from 1975 to 2005. J Clin Oncol 27: 1485-1491, 2009.

2. Cha C, Fong Y, Jarnagin WR, Blumgart LH and DeMatteo RP: Predictors and patterns of recurrence after resection of hepatocellular carcinoma. J Am Coll Surg 197: 753-758, 2003.

3. Guo W, He X, Li Z and Li Y: Combination of transarterial chemoembolization (TACE) and radiofrequency ablation (RFA) vs. surgical resection (SR) on survival outcome of early hepatocellular carcinoma: A meta-analysis. Hepatogastroenterology 62: 710-714, 2015

4. Cheng AL, Kang YK, Chen Z, Tsao CJ, Qin S, Kim JS, Luo R, Feng J, Ye S, Yang TS, et al: Efficacy and safety of sorafenib in patients in the Asia-Pacific region with advanced hepatocellular carcinoma: A phase III randomised, double-blind, placebo-controlled trial. Lancet Oncol 10: 25-34, 2009.
5. Llovet JM, Ricci S, Mazzaferro V, Hilgard P, Gane E, Blanc JF, de Oliveira AC, Santoro A, Raoul JL, Forner A, et al: Sorafenib in advanced hepatocellular carcinoma. N Engl J Med 359: 378-390, 2008.

6. Shirasaka T, Shimamato Y, Ohshimo H, Yamaguchi M, Kato T, Yonekura K and Fukushima M: Development of a novel form of an oral 5-fluorouracil derivative (S-1) directed to the potentiation of the tumor selective cytotoxicity of 5-fluorouracil by two biochemical modulators. Anticancer Drugs 7: 548-557, 1996.

7. Hatano H, Kobayashi S, Nagano H, Tomokuni A, Tomimaru Y, Murakami M, Marubashi S, Eguchi H, Takeda Y, Tanemura M, et al: A case of successful multimodal treatment for combined hepatocellular and cholangiocarcinoma with portal venous tumor thrombus. Gan To Kagaku Ryoho 36: 2374-2376, 2009 (In Japanese).

8. Nakamura M, Nagano H, Wada H, Noda T, Ota H, Damdinsuren B, Marubashi S, Miyamoto A, Takeda Y, Umeshita K, et al: A case of hepatocellular carcinoma with multiple lung, spleen, and remnant liver metastasis successfully treated by combination chemotherapy with the novel oral DPD-inhibiting chemotherapeutic drug S-1 and interferon-alpha. J Gastroenterol 41: 1120-1125, 2006.

9. Suganuma T, Terauchi R, Shikina A, Tanaka M, Aozasa S, Utsunomiya K, Fujino K, Ito H, Okada K, Tsuda T and Hase K: A case of hepatocellular carcinoma with bone metastasis responding to concurrent TS-1/low-dose cisplatin (CDDP) therapy and radiotherapy. Gan To Kagaku Ryoho 31: 781-784, 2004 (In Japanese).

10. Furuse J, Okusaka T, Kaneko S, Kudo M, Nakachi K, Ueno H, Yamashita T and Ueshima K: Phase I/II study of the pharmacokinetics, safety and efficacy of S-1 in patients with advanced hepatocellular carcinoma. Cancer Sci 101: 2606-2611, 2010. 
11. Kudo M, Moriguchi M, Numata K, Hidaka H, Tanaka H, Ikeda M, Kawazoe S, Ohkawa S, Sato Y, Okusaka T, et al: A randomized, double-blind, placebo-controlled phase III study of S-1 in patients with sorafenib-refractory advanced hepatocellular carcinoma (S-CUBE). J Clin Oncol 33 (Supple): abstr $4018,2015$.

12. Salonga D, Danenberg KD, Johnson M, Metzger R, Groshen S, Tsao-Wei DD, Lenz HJ, Leichman CG, Leichman L, Diasio RB and Danenberg PV: Colorectal tumors responding to 5-fluorouracil have low gene expression levels of dihydropyrimidine dehydrogenase, thymidylate synthase, and thymidine phosphorylase. Clin Cancer Res 6: 1322-1327, 2000.

13. Leichman CG, Lenz HJ, Leichman L, Danenberg K, Baranda J, Groshen S, Boswell W, Metzger R, Tan M and Danenberg PV: Quantitation of intratumoral thymidylate synthase expression predicts for disseminated colorectal cancer response and resistance to protracted-infusion fluorouracil and weekly leucovorin. J Clin Oncol 15: 3223-3229, 1997.

14. Lenz HJ, Danenberg KD, Leichman CG, Florentine B, Jonston PG, Groshen S, Zhou L, Xiong YP, Danenberg PV and Leichman LP: p53 and thymidylate synthase expression in untreated stage II colon cancer: Associations with recurrence, survival, and site. Clin Cancer Res 4: 1227-1234, 1998.

15. Kuramochi H, Hayashi K, Uchida K, Miyakura S, Shimizu D, Vallbohmer D, Park S, Danenberg KD, Takasaki K and Danenberg PV: 5-fluorouracil-related gene expression levels in primary colorectal cancer and corresponding liver metastasis. Int $\mathrm{J}$ Cancer 119: 522-526, 2006.

16. Johnston SJ, Ridge SA, Cassidy J and McLeod HL: Regulation of dihydropyrimidine dehydrogenase in colorectal cancer. Clin Cancer Res 5: 2566-2570, 1999.

17. Peng Y, Qi X and Guo X: Child-pugh versus MELD score for the assessment of prognosis in liver cirrhosis: A systematic review and meta-analysis of observational studies. Medicine (Baltimore) 95: e2877, 2016.

18. Livak KJ and Schmittgen TD: Analysis of relative gene expression data using real-time quantitative PCR and the 2(-Delta Delta C(T)) Method. Methods 25: 402-408, 2001

19. Nii A, Shimada M, Ikegami T, Harino Y, Imura S, Morine Y, Kanemura H, Arakawa Y and Sugimoto K: Significance of dihydropyrimidine dehydrogenase and thymidylate synthase mRNA expressions in hepatocellular carcinoma. Hepatol Res 39: 274-281, 2009
20. Takahashi T, Yoshida H, Mamada Y, Taniai N, Mizuguchi Y, Shimizu T, Kakinuma D, Ishikawa Y, Akimaru K, Sugisaki Y and Tajiri T: Profiling of fluorouracil-related genes by microdissection technique in hepatocellular carcinoma. Hepatogastroenterology 54: 1612-1616, 2007.

21. Lenz HJ, Hayashi K, Salonga D, Danenberg KD, Danenberg PV, Metzger R, Banerjee D, Bertino JR, Groshen S, Leichman LP and Leichman CG: p53 point mutations and thymidylate synthase messenger RNA levels in disseminated colorectal cancer: An analysis of response and survival. Clin Cancer Res 4: 1243-1250, 1998.

22. Metzger R, Leichman CG, Danenberg KD, Danenberg PV, Lenz HJ, Hayashi K, Groshen S, Salonga D, Cohen H, Laine L, et al: ERCC1 mRNA levels complement thymidylate synthase mRNA levels in predicting response and survival for gastric cancer patients receiving combination cisplatin and fluorouracil chemotherapy. J Clin Oncol 16: 309-316, 1998.

23. Edler D, Glimelius B, Hallström M, Jakobsen A, Johnston PG, Magnsson I, Ragnhammar P and Blomgren H: Thymidylate synthase expression in colorectal cancer: A prognostic and predictive marker of benefit from adjuvant fluorouracil-based chemotherapy. J Clin Oncol 20: 1721-1728, 2002.

24. Koumarianou A, Tzeveleki I, Mekras D, Eleftheraki AG, Bobos M, Wirtz R, Fountzilas E, Valavanis C, Xanthakis I, Kalogeras KT, et al: Prognostic markers in early-stage colorectal cancer: Significance of TYMS mRNA expression. Anticancer Res 34: 4949-4962, 2014.

25. Zhao HY, Ma GW, Zou BY, Li M, Lin SX, Zhao LP, Guo Y, Huang Y, Tian Y, Xie D and Zhang L: Prognostic significance of thymidylate synthase in postoperative non-small cell lung cancer patients. Onco Targets Ther 7: 1301-1310, 2014.

26. Nakano M, Tanaka M, Kuromatsu R, Nagamatsu H, Sakata K, Matsugaki S, Kajiwara M, Fukuizumi K, Tajiri N, Matsukuma N, et al: Efficacy, safety, and survival factors for sorafenib treatment in Japanese patients with advanced hepatocellular carcinoma. Oncology 84: 108-114, 2013. 